\title{
A Methodology for Conducting National-Scale Alluvial Diamond Resource Potential and Production Capacity Assessments, with a Focus on Artisanal Mining
}

\section{Introduction}

In May of 2000, a meeting was convened in Kimberley, South Africa, by representatives of the diamond industry and leaders of African governments to develop a certification process intended to assure that export shipments of rough diamonds were free of conflict concerns. Outcomes of the meeting were formally supported later in December of 2000 by the United Nations in a resolution adopted by the General Assembly. By 2002, the Kimberley Process Certification Scheme was ratified and signed by diamond-producing and diamond-importing countries. As of August 2012, the Kimberley Process (KP) had 51 participants representing 77 countries.

It is often difficult to obtain independent verification of the diamond production statistics that are provided to the KP. However, some degree of independent verification can be obtained through an understanding of a country's naturally occurring endowment of diamonds and the intensity of mining activities. Studies that integrate these two components can produce a range of estimated values for a country's diamond production, and these estimates can then be compared to the production statistics released by that country.

This methodology is used to calculate (1) the diamond resource potential of a country, which refers to the total number of carats estimated to be remaining in the country, and (2) the diamond production capacity of a country, which is the current volume of diamonds that may realistically be produced per year utilizing current human and physical resources. The following sections outline the methodology used by the U.S. Geological Survey (USGS) to perform diamond assessments in Mali, the Central African Republic, Ghana, and Guinea (Chirico and others 2010a, b, c; in press).
Figure 1. A satellite image of a mining site in Guinea. The visible mining areas have been delineated in red and added to the digital database of diamond occurrences. The USGS GPS track route is from fieldwork done in March 2010.

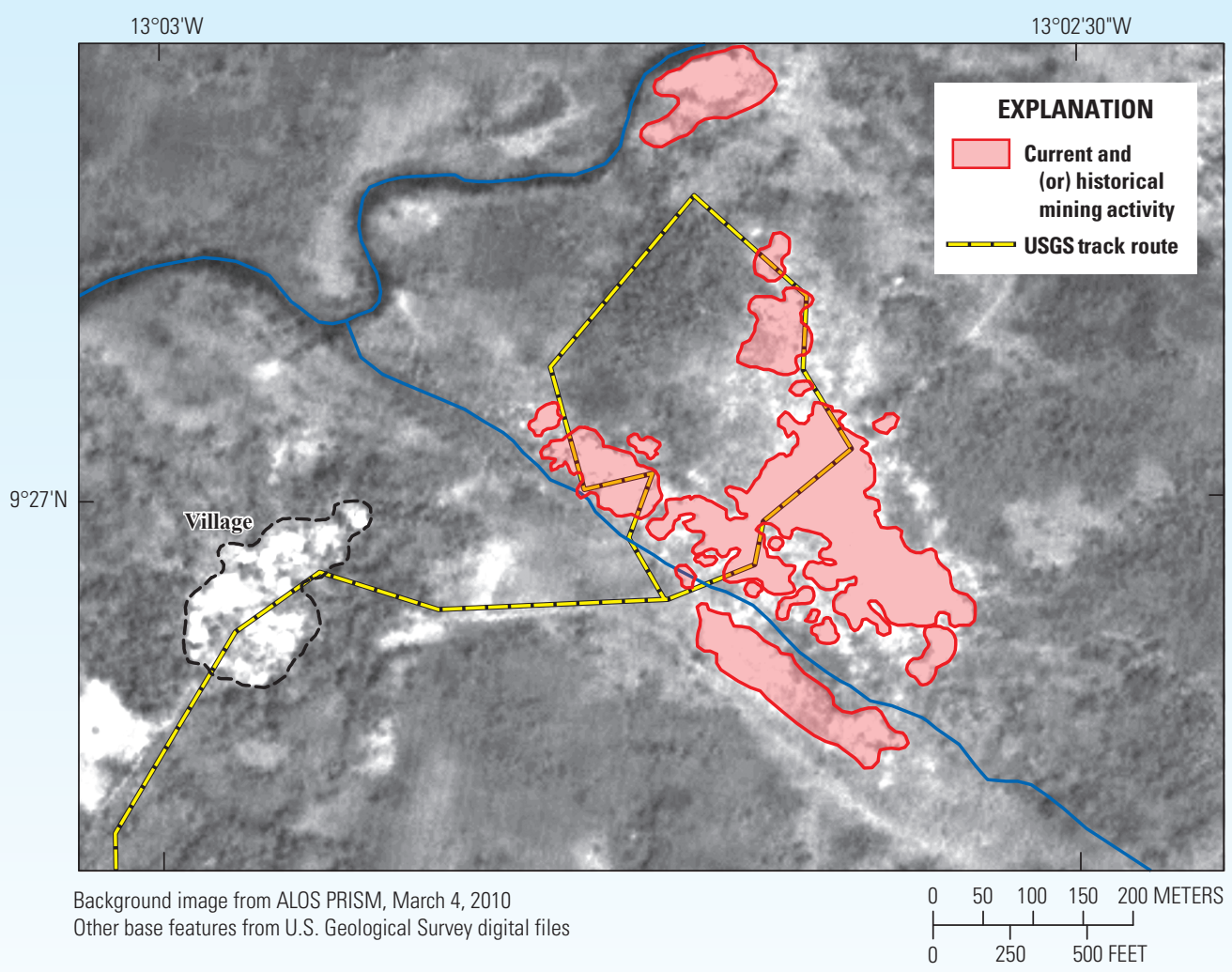

Background image from ALOS PRISM, March 4, 2010 


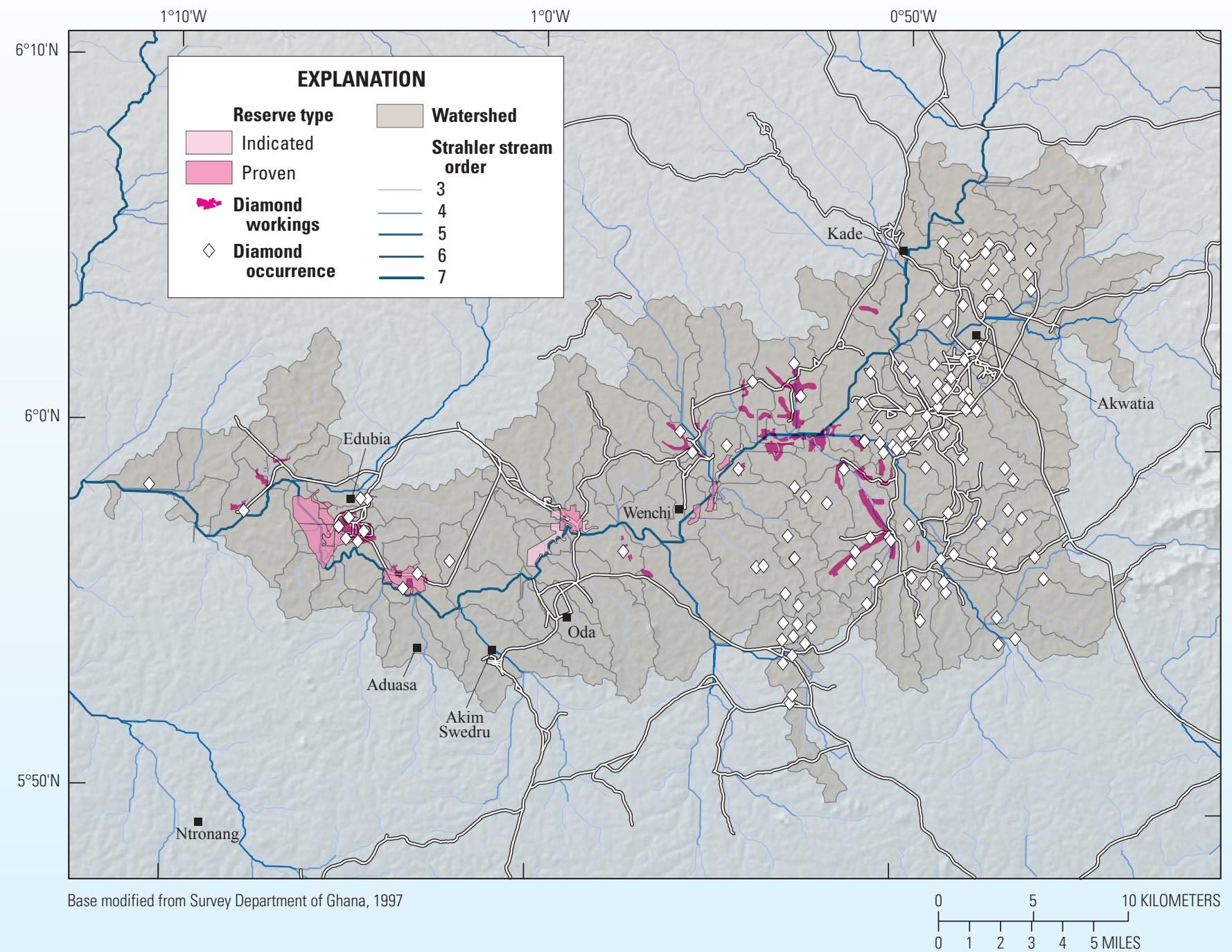

Figure 2. The hydrologic model produced for the Birim watershed, Ghana.

\section{Methodology}

\section{Bibliographic and Historical Research}

The first step of the methodology includes the research, collection, and organization of all available data related to diamond resources and production in the country of interest. All available reports documenting occurrences of diamonds are collected, including reports by private mining companies, geophysical studies, geologic maps, and journal articles. A digital database of diamond occurrences is then developed from these sources. The digital database consists of a record for each known occurrence with attribute information on the size of the deposit, grade, and so on.

\section{Field Assessment}

Field mapping is conducted at several sites within the study area in order to develop a database of information on the terrain, geomorphology, geology, mineral deposits, and current mining activities of the area. To ensure the accurate and consistent collection of data, a comprehensive questionnaire was developed and is used in gathering information in the field. The data gathered during the field assessment are then incorporated into the digital database of diamond occurrences.

\section{Remote Sensing}

Satellite imagery of the study sites is acquired and analyzed to map the extent of all visible diamond mining areas (fig. 1). Satellite images can also be used to document whether a site is active or inactive or to map changes over time at the site. This technique involves using imagery to estimate the volume of material worked at a site, and this information helps to determine the productivity of miners at a deposit. 


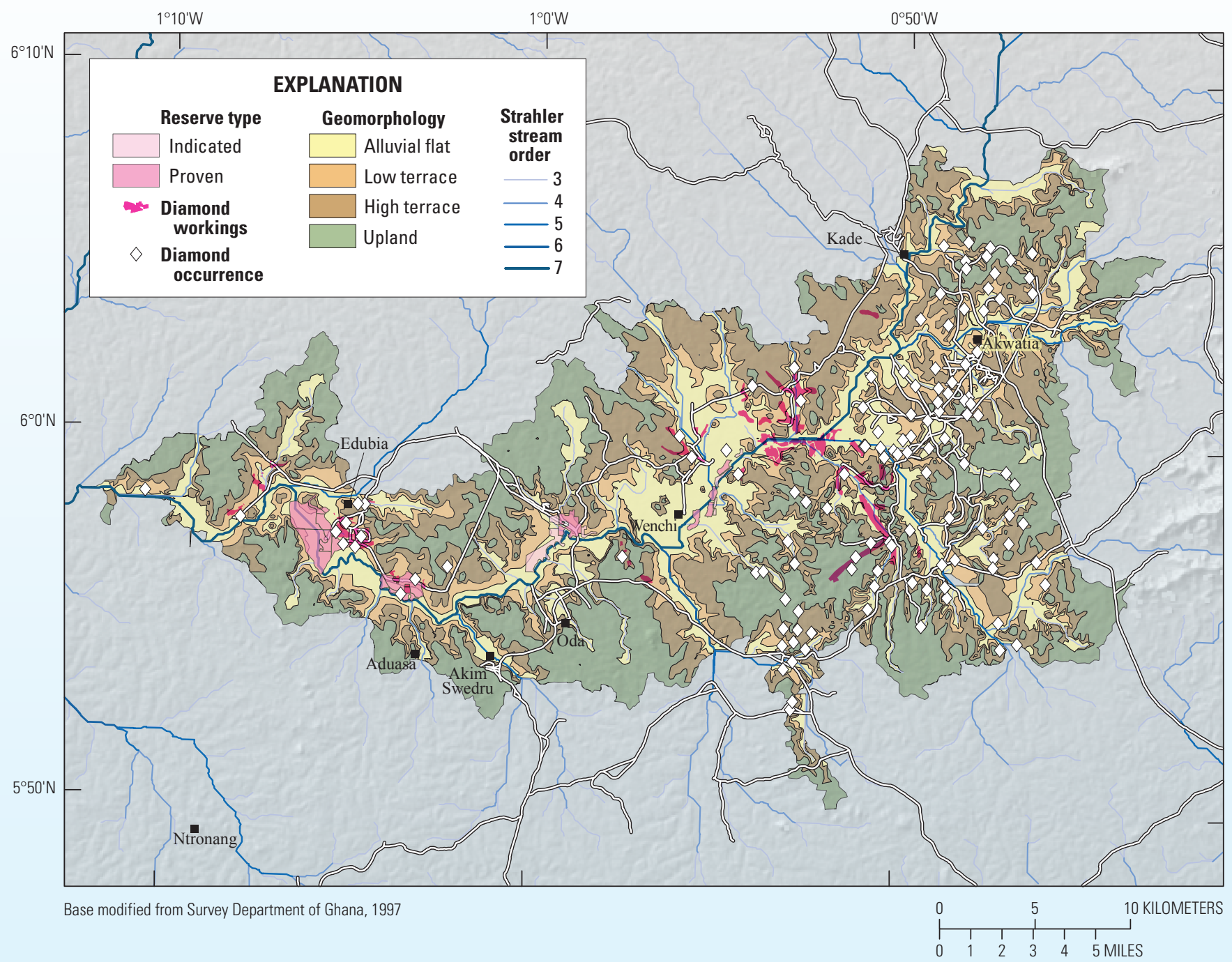

Figure 3. The geomorphic model produced for the Birim watershed, Ghana.

\section{Geographic Information Systems}

Occurrences in the diamond database are attributed with geographic coordinates so that the occurrences can be mapped and the spatial distribution of the deposits can be examined in a geographic information system (GIS). The locations of occurrences are then used in further hydrologic and geomorphic modeling of the diamond mining areas.

\section{Hydrologic Analysis}

A GIS model of diamond-bearing river basins is created from a digital elevation model (DEM) using the Strahler (1964) stream order system (fig. 2). The analysis is performed only on subbasins containing a diamond occurrence, as it is often unlikely that the entire watershed is diamondiferous. The logic behind the Strahler system is that the stream order number is directly proportional to the size of the contributing watershed, to channel dimensions, and to stream-discharge measurements for each stream segment. Typically, the hydrologic model develops subbasins for Strahler order 2 and higher stream segments, although order 1 segments may also be delineated for site-specific analysis.

\section{Geomorphic Modeling}

Closely related to the hydrologic analysis, the geomorphic model uses a DEM to calculate the geographic extent of the alluvial flat, low terrace, and high terrace landforms within each of the diamondiferous subbasins (fig. 3). Mapping the geomorphology is critical, as previous research has established that diamond deposit grades are correlated with their location in either alluvial flat or terrace formations. Using the geomorphic model, the volume and grade of deposits in the selected subbasins are calculated on the basis of surface area of the flats and terraces, available grade data, and geomorphic measurements of the diamondiferous gravel layer thickness determined from field measurements. 


\section{Diamond Resource Potential Formula}

Diamond resource potential is calculated using the volume and grade methodological approach. This mathematical analysis relies on volume and grade data. The volume of alluvium is determined by estimating the width of the alluvial flat deposit and multiplying it by the thickness of the gravel layer being mined. Different gravel deposits may have higher concentrations of diamonds, so to account for these variations two gravel grades are typically used in the formula. The first is the "basic" grade and is applied to a large percentage of the alluvial gravels, while the second is the "concentration" grade and is applied to the remaining percentage of the alluvial gravels. The ratio of "basic" to "concentration" grade gravels is determined on the basis of the characteristics of the specific study area.

\section{Diamond Production Capacity Formula}

A mathematical formula is also used to calculate diamond production capacity. This formula relies on the following variables: the volume of material worked per digger per day, the average gravel grade, the total number of days a digger works per year, estimated industrial production, and the total number of diggers estimated to be actively mining diamonds.

\section{Conclusion}

This methodology provides a quantitative analytical technique that may be used to assess alluvial diamond resources. The results of the methodology are limited by the availability of input data, yet the results provide a basic level of information on reserves and capacity. As more data are collected, these estimates may be recalculated to produce results with greater accuracy.

\section{References Cited}

Chirico, P.G., Barthélémy, Francis, and Koné, Fatiaga, 2010a, Alluvial diamond resource potential and production capacity assessment of Mali: U.S. Geological Survey Scientific Investigations Report 2010-5044, 23 p.

Chirico, P.G., Barthélémy, Francis, and Ngbokoto, F.A., 2010b, Alluvial diamond resource potential and production capacity assessment of the Central African Republic: U.S. Geological Survey Scientific Investigations Report 2010-5043, 22 p.

Chirico, P.G., Malpeli, K.C., Anum, Solomon, and Phillips, E.C., 2010c, Alluvial diamond resource potential and production capacity assessment of Ghana: U.S. Geological Survey Scientific Investigations Report 2010-5045, 25 p.

Chirico, P.G., Malpeli, K.C., Van Bockstael, Mark, Diaby, Mamadou, Cissé, Kabinet, Diallo, T.A., and Sano, Mahmoud, in press, Alluvial diamond resource potential and production capacity assessment of Guinea: U.S. Geological Survey Scientific Investigations Report.

Strahler, A.N., 1964, Quantitative geomorphology of drainage basins and channel networks, in Chow, V.T., ed., Handbook of applied hydrology: McGraw-Hill, p. 4-40.

\section{Additional Information}

Peter G. Chirico

12201 Sunrise Valley Drive

National Center, MS 926A

Reston, VA 20192

pchirico@usgs.gov
Katherine C. Malpeli 12201 Sunrise Valley Drive National Center, MS 926A Reston, VA 20192 kmalpeli@usgs.gov

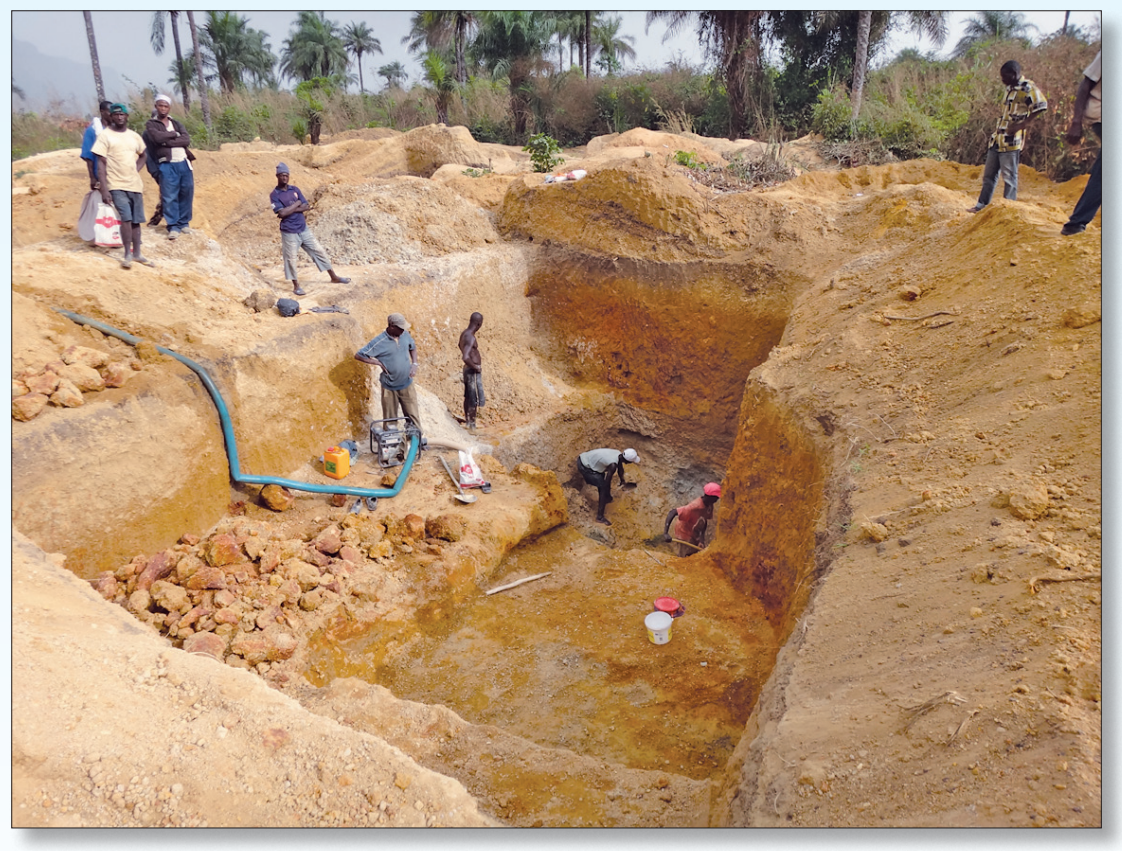

An artisanal mine site visited during fieldwork in Forécariah, Guinea. 